\title{
Food and drug reactions, wheezing, and eczema in preterm infants
}

\author{
A Lucas, O G Brooke, T J Cole, R Morley, M F Bamford
}

\begin{abstract}
Allergic reactions were investigated in 777 preterm infants . who were randomly assigned to early diet and followed up to 18 months post term. Wheezing or asthma was common (incidence 23\%); it was associated with neonatal ventilation, maternal smoking, and a family history of atopy and was unexpectedly reduced in babies born by caesarean section. Even in non-ventilated infants, the incidence of subsequent wheezing was $18 \%$, rising to an estimated $44 \%$ (using logistic regression) when the foregoing risk factors (excluding ventilation) were present. Eczema occurred in 151 infants (19\%) and was strongly associated with multiple pregnancy (30\% incidence in twins or triplets). Reactions to cows' milk (incidence: $4.4 \%$ from detailed history; $0.8 \%$ confirmed by challenge), other foods $(10 \%)$, and drugs (5\%) were within the range reported in full term infants. Milk and food reactions were associated with multiple pregnancy (19\%) and a family history of atopy. Reactions to drugs were least likely to occur in infants who had been ventilated and were on multiple medications in the neonatal period, suggesting that drug tolerance may have developed. We speculate that preterm infants may be a high risk group for asthma and eczema, which could imply an association between atopy and prematurity.
\end{abstract}

It is reasonable to suppose that preterm infants would be vulnerable to an increased incidence of later allergic reactions. They are commonly exposed to cows' milk antigens at a time when exclusion of whole antigenic proteins by the gut is poor, ${ }^{1}$ and they are vulnerable to milk aspiration, a potent source of sensitisation. ${ }^{2}$ They may also consume a greater load of food antigens for their size than mature infants, and have previously been shown to develop latent anaphylactic sensitisation to cows' milk. ${ }^{3}$ Moreover, premature babies are often heavily exposed to numerous drugs to which they might be sensitised. On the other hand, there is some evidence that preterm infants may be less liable to clinical sensitisation than more mature infants. For example, IgE production does not seem to occur before about 36 weeks' gestation. ${ }^{4}$ It is possible that increased antigen absorption from the gut may act as a suppressant to antibody production, ${ }^{5}$ a proposal supported by work in lower primates ${ }^{6}$ and by the finding of an increased population of suppressor $\mathrm{T}$ cells. ${ }^{7}$ Infants born very prematurely may also have less exposure to maternal anti-idiotype anti- bodies, which are thought to be important in the pathogenesis of childhood atopy. ${ }^{8} 9$ Despite these considerations, allergic reactions and the factors relating to them have been poorly documented in such infants. This paper reports data on allergic reactions in 777 infants born preterm who were followed up to 18 months of corrected age.

\section{Subjects and methods}

The subjects in this investigation are currently taking part in a five centre study designed to investigate the effects of early diet on later outcome in preterm infants. The overall objectives, study population, and design of this study have already been described. ${ }^{10}$ We report here the incidence of atopic or allergic disease in 777 infants who have been followed up until 18 months after the expected date of delivery.

Infants were recruited, with informed parental consent, in Cambridge, Ipswich, Kings Lynn, Norwich, and Sheffield. All infants weighed less than $1850 \mathrm{~g}$ at birth and were without major congenital abnormality. Mean (SD) birth weight was 1397 (298) $\mathrm{g}$ and mean gestation $31.0(2.7)$ weeks. Details of atopic or allergic disease in the family were recorded while the infant was in the neonatal unit.

Infants in centres 1-3 were first seen for follow up at 9 (1) months' corrected age, and infants in all five centres were seen at 18 (1) months' corrected age. At the follow up examinations information was collected on eczema, wheezing (asthma), and food or drug sensitivities (see below). The history was supported as far as possible by clinical examination.

A single observer (RM) recorded the historical data in centres $1-4$, achieving a follow up rate of over $95 \%$. While other observers were involved at centre 5 , in all cases they were blind to the infants' clinical course and management during the neonatal period.

Reactions to specific foods were classified as follows. (1) Cases with a convincing history of reaction(s) to a specific agent, resulting in its exclusion from the diet on professional advice. Such reactions were usually gastrointestinal or dermatological. (2) Cases where specific symptoms recurred on challenge conducted under controlled conditions. Reactions to drugs and household agents, mainly dermatological, were recorded similarly.

There has been much debate on the definition of asthma in infancy and childhood. ${ }^{11}$ Godfrey suggests that the diagnosis should be based on intermittent cough or wheeze that can be reversed, largely or completely, by bronchodila- 
tors or steroids. ${ }^{12}$ It is uncertain, however, whether recurrent untreated wheezing should be classified as asthma. We have used three categories: (a) 'recurrent wheezing', which refers to infants with at least three episodes of wheezing recorded by careful history, but where no drug treatment has been used; (b) 'moderate asthma': cough and wheeze requiring drug treatment either intermittently or continuously; and (c) 'severe asthma': cases requiring one or more hospital admissions for acute asthma. Other respiratory conditions characterised by noisy breathing, for example mucous rattling, were as far as possible excluded.

Atopic eczema was diagnosed from a clear history of itchy dermatitis with characteristic distribution, confirmed by clinical examination when active at the time of interview $(60 \%$ of cases). Seborrhoeic dermatitis was not classified as eczema. Disease severity was classified as mild, requiring no treatment, moderate, requiring intermittent treatment (for example, steroid applications), and severe, reflecting the need for intensive treatment, usually after specialist referral.

Statistical analysis was by $\chi^{2}$ test and multiple logistic regression analysis.

The study was approved by the local health authority ethics committee at each of the five hospitals and the Dunn Nutrition Unit.

\section{Results}

INCIDENCE OF ATOPIC OR ALLERGIC DISEASE Table 1 shows the prevalence of atopic/allergic diseases in the 777 infants at 18 months' corrected age. Overall incidence of wheezing by this age was $22 \cdot 5 \%(175 / 777)$ and of eczema $19 \cdot 4 \%(151 / 777)$. Reactions to foods occurred in $10 \%(81 / 777)$ and to drugs in $5 \%(42 / 777)$. In all, 341 infants $(44 \%)$ had had one or more manifestations of 'allergic' or atopic disease by 18 months of age.

All the atopic or allergic conditions investigated were highly correlated with one another.

Table 1 Incidence of wheezing or asthma, eczema, and food and drug reactions at 18 months' corrected age in 777 infants born preterm

\begin{tabular}{|c|c|c|}
\hline & $\begin{array}{l}\text { No of } \\
\text { cases }\end{array}$ & Incidence (\%) \\
\hline $\begin{array}{l}\text { Asthma or wheezing*: } \\
\text { All cases } \\
\text { Intermittent wheezing } \\
\text { Moderate asthma } \\
\text { Severe asthma }\end{array}$ & $\begin{array}{r}175 \\
117 \\
46 \\
12\end{array}$ & $\begin{array}{r}22 \cdot 5 \\
15 \cdot 1 \\
5 \cdot 9 \\
1 \cdot 5\end{array}$ \\
\hline $\begin{array}{l}\text { Eczema*: } \\
\text { All cases } \\
\text { Mild } \\
\text { Moderate } \\
\text { Severe }\end{array}$ & $\begin{array}{r}151 \\
48 \\
97 \\
6\end{array}$ & $\begin{array}{r}19 \cdot 4 \\
6 \cdot 2 \\
12 \cdot 5 \\
0 \cdot 8\end{array}$ \\
\hline $\begin{array}{l}\text { Food reactions: } \\
\text { All casest (one or more food) } \\
\text { Cows' milk } \\
\text { Positive history } \\
\text { Confirmed by challenge } \\
\text { Egg } \\
\text { Other foods (including additives) }\end{array}$ & $\begin{array}{r}34 \\
6 \\
14 \\
39\end{array}$ & $\begin{array}{l}4 \cdot 4 \\
0 \cdot 8 \\
1 \cdot 8 \\
5 \cdot 0\end{array}$ \\
\hline $\begin{array}{l}\text { Drug reactions: } \\
\text { All cases } \\
\text { Penicillin }\end{array}$ & $\begin{array}{l}42 \\
25\end{array}$ & $\begin{array}{l}5 \cdot 4 \\
3 \cdot 2\end{array}$ \\
\hline $\begin{array}{l}\text { One or more of the above conditions } \\
\text { or reactions: }\end{array}$ & 341 & 43.9 \\
\hline
\end{tabular}

*For definitions see text.

tReported reactions to foods where usually specific to one food only six cases reacted to two foods and none to more than two.
Children with eczema were more than twice as likely to experience food reactions as children without eczema $(27 / 151$ (18\%) compared with $54 / 626(9 \%) ; p<0.001)$, and significantly more likely to have asthma or wheezing $(47 / 175(27 \%)$ compared with $104 / 602(17 \%) ; p<0.005$.)

FACTORS ASSOCIATED WITH THE DEVELOPMENT OF ATOPIC OR ALLERGIC DISEASE

(a) Wheezing or asthma

Using logistic regression, factors examined for an independent association with wheezing or asthma (dependent variable) were: sex, birth weight, gestation, mode of delivery (vaginal or caesarean), days of mechanical ventilation (log transformed and +1 to avoid $\log 0$ ), multiple pregnancy (twins or triplets), maternal steroids before delivery, small for gestational age (birth weight $<10$ th centile), pregnancy induced hypertension (systolic blood pressure $>140$ $\mathrm{mmHg}$, diastolic blood pressure $>90 \mathrm{mmHg}$ ), social class of parents, number of cigarettes smoked by mother and father, and number of first degree relatives with a history of allergic disease (asthma, eczema, hay fever, drug reactions, or proved food sensitivities). The only factors to emerge as independently related to wheezing or asthma were: duration of mechanical ventilation $(p<0.001)$, mode of delivery $(p<0.01)$, family history of allergy $(p<0.01)$, and maternal smoking $(\mathrm{p}<0 \cdot 01)$. The odds ratio of the infant developing wheezing or asthma in association with each factor is shown in table 2 . The constant in the regression model shown was set as the 'best case' (lowest incidence of wheezing), which occurred in babies born by caesarean section from non-smoking mothers, who had no close family history of allergy and required no ventilation (relative risk 0.13:1; equivalent to an incidence of $11 \cdot 5 \%$ ). From the regression equation presented, the absolute risk of wheezing, based on the 'risk factors' shown, can be estimated from the constant and individual regression coefficients. Thus a nonventilated infant with two atopic first degree relatives and who was delivered vaginally to a mother smoking 20 cigarettes per day, would have a relative risk of $0 \cdot 8: 1$ (equivalent to $44 \%$ incidence). Table 3 shows raw data for the incidence and prevalence of wheezing or asthma broken down into categories for each of the significantly associated factors identified by the regression analysis. Notably $38 \%$ of infants ventilated for 10 days or more developed wheezing or asthma subsequently. No correlation at all was found between birth month and the development of asthma, in contrast to the findings in full term infants. ${ }^{13} 14$

\section{(b) Eczema}

Using logistic regression (table 2), with independent variables as described above, the only factor found to be independently related to the incidence of eczema was multiple pregnancy (twins or triplets), which increased the relative odds by $2 \cdot 1: 1(\mathbf{p}<0.001)$. Raw data (table 3$)$ show an incidence of eczema of $30 \%$ in twins or triplets (39/130 cases) compared with $17 \%$ in singletons $(p<0 \cdot 005)$. 
Table 2 Relative odds of (a) wheezing or asthma or (b) eczema for each significantly associated factor identified by multiple logistic regression

\begin{tabular}{|c|c|c|c|c|}
\hline Factor & $\begin{array}{l}\text { Regression } \\
\text { coefficient }\end{array}$ & $S E$ & Relative odds & \\
\hline \multicolumn{5}{|l|}{ (a) Wheezing or asthma } \\
\hline Vaginal delivery & 0.50 & $0 \cdot 18^{*: *}$ & $1 \cdot 6: 1 \|$ & \\
\hline \multirow[t]{2}{*}{ Duration of ventilation } & $0.34 \dagger$ & $0 \cdot 08^{* * * \cdots}$ & $\begin{array}{l}1 \cdot 6: 1 \text { for } 3 \\
2 \cdot 0: 1 \text { for } 7\end{array}$ & days \\
\hline & & & $2 \cdot 6: 1$ for 15 & \\
\hline Cigarettes smoked by mother/day & 0.04 & $0 \cdot 01^{\text {**: }}$ & $\begin{array}{l}1 \cdot 2: 1 \text { for } 5 \\
1 \cdot 5: 1 \text { for } 10 \\
2 \cdot 3: 1 \text { for } 20\end{array}$ & cigarettes/day \\
\hline \multirow{2}{*}{$\begin{array}{l}\text { No of first degree relatives with history of allergył } \\
\text { Constant (best case) } \\
end{array}$} & $0 \cdot 25$ & $0 \cdot 10^{*}$ & $\begin{array}{l}1 \cdot 3: 1 \text { for } 1 \\
2 \cdot 1: 1 \text { for } 2\end{array}$ & relative \\
\hline & $-2 \cdot 03$ & & $0 \cdot 13: 1$ & \\
\hline \multirow{3}{*}{$\begin{array}{l}\text { (b) Eczema } \\
\text { Multiple birth } \\
\text { Constant (best case) }\end{array}$} & & & & \\
\hline & 0.72 & $0 \cdot 22^{\text {*****: }}$ & $2 \cdot 0: 1$ & \\
\hline & $-1 \cdot 56$ & & $0 \cdot 21: 1$ & \\
\hline
\end{tabular}

Table 3 Raw data on overall incidence and prevalence at 18 months of wheezing, eczema, and food sensitivities, broken down by factors shown to be significantly related using logistic regression analysis (see table 2)

\begin{tabular}{|c|c|c|}
\hline & $\begin{array}{l}\text { Proportion of cases } \\
(\% \text { incidence })\end{array}$ & p Value \\
\hline \multicolumn{3}{|l|}{$\begin{array}{l}\text { Asthma or wheezing: } \\
\text { (a) Ventilation }\end{array}$} \\
\hline $\begin{array}{l}\text { None } \\
1-9 \text { days } \\
>10 \text { days }\end{array}$ & $\begin{array}{l}72 / 410(18) \\
75 / 294(26) \\
28 / 73(38)\end{array}$ & $<0.0001$ \\
\hline $\begin{array}{l}\text { (b) Parental smoking } \\
\text { No } \\
\text { Yes }\end{array}$ & $\begin{array}{r}107 / 545(20) \\
68 / 232(29)\end{array}$ & $<0.005$ \\
\hline $\begin{array}{l}\text { (c) Caesaerean section } \\
\text { No } \\
\text { Yes } \\
\text { (d) Family history of allergy } \\
\text { (i) All cases }\end{array}$ & $\begin{array}{l}103 / 382(27) \\
72 / 395(18)\end{array}$ & $<0.005$ \\
\hline $\begin{array}{l}\text { No } \\
\text { Yes } \\
\text { (ii) Cases still symptomatic } \\
\text { at } 18 \text { months }\end{array}$ & $\begin{array}{r}104 / 577(22) \\
51 / 200(26)\end{array}$ & $>0.05$ \\
\hline $\begin{array}{l}\text { No } \\
\text { Yes }\end{array}$ & $\begin{array}{l}82 / 577(14) \\
45 / 200(23)\end{array}$ & $<0.01$ \\
\hline \multicolumn{3}{|l|}{ Eczema: } \\
\hline $\begin{array}{l}\text { No } \\
\text { Yes }\end{array}$ & $\begin{array}{r}112 / 647(17) \\
39 / 130(30)\end{array}$ & $<0.005$ \\
\hline \multicolumn{3}{|l|}{$\begin{array}{l}\text { Food sensitivities: } \\
\text { Multiple pregnancy }\end{array}$} \\
\hline $\begin{array}{l}\text { No } \\
\text { Yes } \\
\text { Family history of allergies }\end{array}$ & $\begin{array}{l}57 / 647(9) \\
24 / 130(19)\end{array}$ & $<0.005$ \\
\hline $\begin{array}{l}\text { No } \\
\text { Yes }\end{array}$ & $\begin{array}{l}51 / 577 \text { (9) } \\
30 / 200 \text { (15) }\end{array}$ & $<0.02$ \\
\hline
\end{tabular}

${ }^{*}$ Family history was a significant factor for overall incidence of asthma when confounding factors were adjusted for - see table 2 .

\section{(c) Reactions to foods and drugs}

Analysis of raw data showed reactions to foods were more common in twins or triplets $(p<0.005)$ and in infants who had a family history of allergy or atopy $(\mathrm{p}<0.02)$ (table 3 ). These findings were confirmed by logistic regression analysis as above. Regression analysis also showed that drug reactions were appreciably more common in infants who were not ventilated (relative risk compared with ventilated infants, $2 \cdot 5: 1$ ), despite lower drug exposure in the neonatal period in this group. There was a trend towards a lower incidence of reactions to penicillin by 18 months in those who had received penicillin in the neonatal period $(2 \cdot 3 \%$; $11 / 473$ cases) compared with those who had not $(4.6 \% ; 14 / 304)$.

The influence of early diet on later allergic disease is an important area in its own right which is not considered in this paper and will be published separately. As described previously, ${ }^{10}$ infants were assigned in three centres to preterm formula and compared with donor breast milk (either as sole diets or as supplements to maternal milk). In the remaining two centres infants were assigned to a standard term formula and compared with a preterm formula (as sole diets or as supplements to maternal milk). For the purpose of interpreting results in this paper, however, our (unpublished) data show that while dietary effects on later allergy emerged in subgroup analyses, there was no overall effect of early diet on later allergic or atopic disease. Thus the conclusions presented here would not be altered if the proportions of infants on each diet were different to those in this study.

\section{Discussion}

In this study we have documented asthma or wheezing, eczema, and food or drug reactions at 18 months post term in nearly 800 infants born preterm. A number of important associations with these outcomes have been identified which may have broader significance for the aetiology of childhood atopy. As we suggest below, however, preterm infants may be, in certain respects, a special group in terms of the evolution of their atopic disease. The apparently high incidence of asthma and wheezing, which was intercorrelated with the incidence of eczema has led us to explore and develop the hypothesis that prematurity may be linked to atopic disease.

Our multicentre study was designed to investigate the effects of early diet (not reported here) on later outcome, including allergic reactions. The experimental design did not require full term control infants, as it was the difference between randomised groups of premature babies that was of importance. The principal purpose in this paper was to explore factors that relate to the development of allergic reactions within our population of preterm infants; again such analyses do not require full term control babies. It was also considered, however, that 
our overall incidence figures for allergic reactions in infants born preterm should be presented here, though it must be emphasised that without using the same data collection procedure on infants born at term any comparison of our incidence figures with those published in term infants are of speculative significance. Nevertheless, such data have been collected in many studies using apparently similar diagnostic criteria to the ones used by us.

It is also reasonable to challenge the reliability of data on food reactions obtained mainly by clinical history. In this large multicentre study detailed immunological tests would have been impracticable and their value controversial. Our study is comparable with others, ${ }^{15-17}$ and has the advantage over several questionnaire based studies $^{13}{ }^{18-20}$ that a careful and consistent history was taken, in four centres, by one observer.

The incidence of wheezing or asthma appeared high. A diagnosis of intermittent wheezing was made at follow up after careful history by an experienced clinician, and moderate or severe 'asthma', requiring drug treatment, had usually been diagnosed by a paediatrician. The incidence of asthma in childhood has been reported to be between $0.1 \%$ and $19 \%$, and even higher (up to $25 \%$ ) if occasional wheezing is included. ${ }^{21}$ However, such high figures have not been reported for infants under 2 years of age. For example, data from the 1970 British cohort study using a questionnaire with less stringent diagnostic criteria than employed here, ${ }^{22}$ showed that by 5 years $21 \%$ of all children had had at least one wheezing episode; yet at 1 year the incidence was only $8.5 \%$, and by 2 years, $11 \cdot 5 \%$ (1318/11 465 cases). From published reports it seems unlikely that intermittent wheezing or frank asthma before 2 years would occur in more than $12 \%$ of infants born at term. Thus our $23 \%$ overall incidence at 18 months strongly suggests an excess in infants born preterm over that in the normal population.

It might be argued that the high rate of wheezing or asthma in infants born preterm is not an atopic manifestation but reflects lung damage after mechanical ventilation for early respiratory disease. Indeed, we found duration of ventilation was strongly associated with later wheezing or asthma, which occurred in nearly $40 \%$ of infants ventilated for 10 days or more. However, we suggest that ventilation was not the sole reason for this excess of cases. Firstly, wheezing or asthma was very common even in infants who received no mechanical ventilation at all, with an $18 \%$ overall incidence in this subgroup, rising to an estimated $44 \%$ in the 'worst case' for non-ventilated infants with other risk factors (see below). Secondly, wheeziness or asthma in this study was strongly associated with a family history of atopy, though only in the case of infants whose wheezing was still problematic at the time of the 18 month follow up. Finally, the incidence of wheezing or asthma was intercorrelated with that of eczema, generally regarded as an atopic disease. We have considered whether our incidence figure for eczema of $19.4 \%$ should be regarded as high. $\mathrm{Kjellman}^{18}$ and Croner et al, ${ }^{19}$ who collected their data in a similar way to ours, reported inci- dence rates of only $7 \cdot 6 \%$ and $5 \cdot 7 \%$ in prospective studies of European (Swedish) term infants. The incidence figures for eczema reported in this country have, however, risen in recent years, from $5 \%$ in the 1946 national birth cohort to $12 \%$ in the 1970 cohort, ${ }^{23}$ though these figures represent incidence up to 6 years of age and cannot be compared with our 18 month incidence. More recent data (1981) from New Zealand, however, showed an incidence of $12 \%$ in 2 year old infants with no atopic family history (compared with $18 \%$ in our study). ${ }^{24}$ Interestingly, though, this study demonstrated that in the subgroup of children with a positive atopic family history, the incidence of eczema (24\%) was similar to ours (25\%). Further study, comparing preterm and term infants using the same data collection procedure, would be needed to examine the possibility raised here, that preterm infants are a high risk group for eczema.

The hypothesis presented that wheezing or asthma in preterm infants may often have an atopic basis requires future investigation. Indeed, the arguments presented above have some inconsistencies: for example, while we show that eczema and wheezing are intercorrelated, these disease states are also to some extent independent as evidenced by a difference in the pattern of associated factors (table 2). Nevertheless, an atopic aetiology for wheezing in preterm infants is further supported by the data of others. Bertrand et al showed that preterm infants, whether ventilated or not, are subject to airways hyper-reactivity. ${ }^{25}$ The tendency to wheeze after mechanical ventilation, observed also in smaller case controlled studies by others, ${ }^{25}{ }^{26}$ could be interpreted as an exacerbating effect of ventilation in infants predisposed, perhaps genetically, to atopic respiratory disease. Furthermore, the association between ventilation and later wheezing could imply that atopic infants are the ones most likely to develop severe early respiratory disease and hence have an increased requirement for ventilation.

Bertrand et al observed that not only do preterm infants have increased 'bronchial hyperreactivity' but so also do their mothers, ${ }^{25}$ raising the intriguing possibility that hyper-reactivity of the smooth muscle in the bronchi could be associated with hyper-reactivity of that of the uterus, as a potential mechanism for preterm labour. This concept is debated however; Chan et al were unable to substantiate Bertrand's hypothesis. ${ }^{27}$ We did not perform bronchial hyper-reactivity tests and the number of mothers with frank asthma was too small for detailed analysis. Nevertheless, our surprising observation that preterm infants delivered by caesarean section were less likely to develop later wheeziness could be explained if it is argued that the great majority of such babies were delivered interventively, largely for complications arising in pregnancy, and therefore they constituted a different group, in terms of familial atopy risk, to those whose mothers went into spontaneous preterm labour.

In contrast to the high incidence of wheezing in preterm infants, the incidence of cows' milk 
reactions $(4 \cdot 4 \%$ based on clinical history; $0 \cdot 8 \%$ confirmed by objective challenge) and of reactions to foods in general $(10 \%)$, was well within the range reported for normal children, in whom incidence of food allergies has been claimed to be as high as $20-40 \%$. $^{1719} 2829$

Few investigators have published incidence figures for drug reactions in early childhood, but Croner's value of $7 \cdot 3 \%$ (116 cases in 1701 infants) was similar to our figure of $5 \cdot 4 \%$ (42/ 779). ${ }^{19}$ Yet, in view of the very high antibiotic and drug usage in low birthweight infants a high rate of subsequent drug reactions might be predicted. On the contrary, the $2 \cdot 5$ fold greater risk of drug reactions in well, non-ventilated compared with sick, ventilated infants (the latter receiving more drugs), together with the trend towards a lower rate of penicillin reactions in infants who had received penicillin in the neonatal period, suggests that preterm infants may develop tolerance to drugs.

Aetiological factors for atopic disease and allergic reactions in preterm infants may not be the same as those factors proposed for babies born at term. For instance, there was no suggestion that any of the outcome responses in this study had a seasonal incidence, as has been found with atopy in full term infants. ${ }^{13}{ }^{14} \mathrm{An}$ unexpected independent association, which demands further exploration, and not described in full term infants, is the raised incidence of eczema and food sensitivity in twins and triplets: indeed for both eczema and food sensitivities multiple birth emerged as the most strongly associated factor. Various studies have examined the concordance of eczema in monozygotic and dizygotic twins ${ }^{30}{ }^{31}$; but if twinning per se is associated with eczema, we may question the validity of such concordance studies regarding the genetic risk for eczema in the population. Maternal smoking, as in term pregnancies, ${ }^{32}$ emerged as a strongly associated independent factor for wheezing or asthma in the infant. The association between atopic disease or food sensitivities in the preterm baby and a family history of atopy suggests that genetic factors were of major aetiological significance.

Perhaps the most important questions raised by our data, and requiring further exploration are: whether wheezing and eczema do indeed have an increased incidence in preterm infants; whether or not wheezing in such infants should be regarded as having principally an atopic basis; whether prematurity is linked to atopic disease; and finally, whether atopy has aetiological importance in preterm labour.

1 Roberton DM, Paganelli R, Dinwiddie R, Levinsky RJ. Milk antigen absorption in the preterm and term neonate. Arch Dis Child 1982;57:369-72.

2 Muller W, Rieger CHL, van der Hardt H. Increased concentrations of milk antibodies in recurrent pulmonary aspiration in infants and young children. Acta Paediatr Scand 1985;74:660-3.
3 Lucas A, McLaughlin P, Coombs RRA. Latent anaphylactic sensitization of infants of low birthweight to cows' milk proteins. Br Med $\mathcal{F}$ 1984;289:1254-6.

4 Michel FB, Bousquet J, Greillier P, Robinet-Levy M, Coulomb Y. Comparison of cord blood immunoglobulin E concentrations and maternal allergy for the prediction of concentrations and maternal allergy for the prediction of
atopic diseases in infancy. F Allergy Clin Immunol 1980; atopic disease

5 Helms I, Rieger CHL. Decreased production of specific antibodies to cows' milk proteins in premature infants during the first six months of life. Eur f Pediatr 1987;146:131-4.

6 Rieger CHL, Rothberg RM. Development of the capacity to produce specific antibody to an ingested food antigen in the premature infant. $F$ Pediatr 1975;87:515-8.

7 Pabst HF, Kreth HW. Ontogeny of the immune response as a basis of childhood disease. $\mathcal{F}$ Pediatr 1980;97:519-34.

8 Melander L, Carlsson B, Hanson L-A. Secretory IgA and IgM antibodies to $\mathrm{E}$-coli $\mathrm{O}$ and poliovirus I antigens occur in amniotic fluid, meconium and saliva from newborns. A neonatal immune response without antigenic exposure - a result of anti-idiotype induction? Clin Exp Immunol 1986; 63:555-61.

9 Falth-Magnusson K, Oman H, Kjellman N-I M. Maternal abstention from cow milk and egg in allergy risk pregabstention from cow milk and

10 Lucas A, Gore SM, Cole TJ, et al. Multicentre trial on feeding low birthweight infants: effects of diet on early growth. Arch Dis Child 1984;59:722-30.

11 Price J. Asthma in children: diagnosis. $\mathrm{Br} \mathrm{Med} \mathcal{F} 1984$; 288:1666-8.

12 Godfrey S. What is asthma? Arch Dis Child 1985;60: 997-1000.

13 Bisgaard H, Dalgaard P, Nyboe J. Risk factors for wheezing during infancy. Acta Paediatr Scand 1987;76:719-26.

14 Kimpen J, Callaert H, Embrechts P, Bosmans E. Cord blood IgE and month of birth. Arch Dis Child 1987;62:478-82.

15 Van Asperen PP, Kemp AS, Mellis CM. Relationship of diet in the development of atopy in infancy. Clin Allergy 1984; 14:525-32.

16 Savilahti E, Taino V-M, Salmenpera L, Siimes MA, Perheentupa J. Prolonged exclusive breast feeding and heredity as determinants in infantile atopy. Arch Dis heredity as determinant

17 Lindfors A, Enocksson E. Development of atopic disease after early administration of cow milk formula. Allergy $1988 ; 43: 11-6$.

$18 \mathrm{Kjellman} \mathrm{N}-\mathrm{I} \dot{M}$. Atopic disease in seven-year-old children. Acta Paediatr Scand 1977;66:465-71.

19 Croner S, Kjellman N-I M, Eriksson B, Roth A. IgE screening in 1701 newborn infants and the development of atopic disease during infancy. Arch Dis Child 1982;57:364-8.

20 Midwinter RE, Morris AF, Colley JRT. Infant feeding and atopy. Arch Dis Child 1987;62:965-7.

21 Storr J, Barrell E, Lenney W. Rising asthma admissions and self referral. Arch Dis Child 1988;63:774-9.

22 Park ES, Golding J, Carswell F, Stewart-Brown S. Preschoo wheezing and prognosis at 10. Arch Dis Child 1986;61: 642-6.

23 Taylor B, Wadsworth J, Wadsworth M, Peckman C. Changes in the reported prevalence of childhood eczema since the in the reported prevalence of childho

24 Fergusson DM, Horwood LJ, Beatrais AL. Shannon FT Taylor B. Eczema and infant diet. Clin Allergy 1981; 11:325-31.

25 Bertrand JM, Riley SP, Popkin J, Coates AL. The long-term pulmonary sequelae of prematurity. The role of familial airway hyper-reactivity and the respiratory distress syndrome. $N$ Engl f Med 1985;312:742-5.

26 MacLusky IB, Stringer D, Zarfen J, Smallhorn J, Levison H. Cardiorespiratory status in long-term survivors of prematurity, with and without hyaline membrane disease. Pediatr Pulmonol 1986;2:94-102.

27 Chan KN, Noble-Jamieson CM, Elliman A, Bryan EM, Aber VR, Silverman M. Airway responsiveness in low birthweight children and their mothers. Arch Dis Child 1988; 63:905-10.

28 Gerrard JW, Mackenzie JWA, Goluboff N, Garson JZ, Maningas CS. Cow's milk allergy: prevalence and manifesMations in an unselected series of newborns. Acta Paediatr tations in an unselected series

29 Saarinen UM, Kajosaari M, Backman A, Siimes MA. Prolonged breast feeding as prophylaxis for atopic disease. Lancet 1956;ii:163-6.

30 Holm NV, Hennigsen K. Atopic dermatitis. A genetic epidemiologic study in a population-based twin sample. f Am Acad Dermatol 1986;15:487-94.

31 Frisbeck M, Skog E, Ytterborn KH. Delayed type of allergy and atopic disease among twins. Acta Derm Venereol (Stockh) 1968;48:192-7.

32 Fergusson DM, Horwood LJ, Shannon FT. Parental smoking and respiratory illness in infancy. Arch Dis Child 1980 55:358-61. 